\title{
Influence of cathodic-protection-induced hydrogenation on mechanical properties of two ship hull plate steels
}

\author{
Marek Jakubowski, \\ Łukasz Modelski, Marek Podbereski, \\ Gdansk University of Technology
}

\begin{abstract}
Tensile testing and Charpy $V$ impact testing results for two ship hull steels: an ordinary strength steel grade $A$ and a higher strength steel grade AH32 each in both as-received conditions and in hydrogenated by zinc protector in salt water conditions. For both steels the hydrogenation has slightly increased yield stress $\left(R_{e}\right)$ and elongation $(A)$ and has not influenced ultimate tensile strength $\left(R_{m}\right)$, while reduction of area has been unchanged (A steel) or even decreased (AH32 steel) due to the hydrogenation. The effect of the hydrogenation on Charpy tests results has evidently been beneficial: the increase of Charpy energy and of percent fibrosity (ductility) of fracture appearance as well as a shift down of ductile-brittle transition temperatures have been observed. It seems that the present practice to evaluate the mechanical properties of ship steels by testing the specimens without hydrogenation leads to conservative results. The Authors have hypothesized that the beneficial effect of hydrogenation can occur if the deformation rate is fast enough, the notch is sharp enough (although only for specimens hydrogenated in unstressed conditions) and hydrogen concentration is moderate.
\end{abstract}

Keywords: ship steels, hydrogenation, Charpy-V impact test, tensile testing

\section{INTRODUCTION}

A small effluent of cargo occurred during the loading of a small tanker on September 2002. A crack in the bottom plating at the edge of a scallop was detected. Since the buckling of the bottom plating in the considered region of hull was visible, most of experts suggested the crack was an immediate result of the buckling, i.e. deformation-induced stress had been released in the form of the crack. Some analysis and tests made by Jakubowski $[1,2]$ have shown that the explanation was not very probable. However, sacrificial zinc anode was not far from the crack location and it could cause some degree of hydrogenation of steel in this region. Therefore some preliminary tests $[1,2]$ have been carried out in order to explain could the cathodicprotection-induced hydrogenation of steel reduce charpy impact toughness energy and a critical value of plastic deformation in static tension, because the buckling could be caused by quasistatic or dynamic grounding of the ship. The specimens were manufactured of the original bottom plating segment cut off from the buckled region of the ship's bottom close to the considered crack. In order to hydrogenation some specimens were submerged in $3.5 \%$ water solution of $\mathrm{NaCl}$ and coupled to zinc anodes. Both results of tensile testing and Charpy impact tests of hydrogenated and not hydrogenated specimens satisfied requirements of Classification Societies for ship hull steels of ordinary strength. Hydrogenation effect, however, has appeared somehow unexpected.
In tensile testing the values of ultimate tensile strength (UTS) and yield strength (YS) of smooth and notched specimens were practically unaffected by the applied hydrogenation. Values of total elongation after fracture (A) for notched specimens were slightly reduced by hydrogenation (but only one hydrogenated notched specimen was compared to one not hydrogenated specimen), while for smooth specimens hydrogenation caused an increase of A-value from $27 \%$ to $31 \%$ (2 hydrogenated specimens and 2 not-hydrogenated ones). Charpy-V impact toughness was evaluated at the temperature of $15^{\circ} \mathrm{C}$ for three asreceived and three hydrogenated specimens. Impact toughness energy was 30-48 J (average $38 \mathrm{~J}$ ) for not hydrogenated specimens and 63-76 J (average 70.3 J). Fracture surface was ductile in $42-71 \%$ (average 54\%) for not-hydrogenated specimens and in 76-100\% (average ca. 95\%) for hydrogenated ones. Thus hydrogenation of steel appeared to be insignificant (but rather slightly positive) factor in the standard tensile testing conditions, while it evidently positively influenced charpy $\mathrm{V}$ impact toughness of the low carbon steel.

The above mentioned preliminary tensile tests results $[1,2]$ are not totally unexpected. There is a general opinion, that hydrogenation of steels markedly reduce their plastic properties, i.e. elongation (A) and the reduction of area (Z), but this opinion is mainly based on slow strain rate tests (SSRT) results, e.g. [3-7]. Strain rates in standard (so called static) tensile testing are significantly ( 2 or 3 orders of magnitude) higher, than those in SSRT. The standard tensile tests usually show also a reduction 
of plastic properties of steels after hydrogenation, although the reduction is smaller than in SSRT [8-10]. However, Lunarska [11] stated that; "softening or hardening of low carbon mild steels can be expected according to the kind and amount of impurities and to the conditions during hydrogenation process". Some of her investigations results [11] show significant increase of plastic properties of iron whiskers of different orientation due to hydrogenation ( 2 or 3 -fold increase of elongation A). The above mentioned Charpy V impact tests results, i.e. significant increase of impact fracture energy due to hydrogenation $[1,2]$ were more unexpected than the tensile testing results.

The Author has formulated a working hypothesis that the influence of hydrogenation of steels on their mechanical properties can change from very negative for very slow strain rates (SSRT), through approximately neutral for medium strain rates (standard tensile testing), up to positive for very high strain rates (impact testing). The hypothesis is based, however, on the Author's preliminary tests on a small population of specimens, and only some of the Archakov's [12] test results corroborated positive effect of hydrogenation on Charpy toughness of steel. Juraszek's et al investigations [13] have shown that Charpy V specimens of a ship steel did not fracture when they had been pre-exposed in salt water and they fractured when pre-exposed in laboratory air, and it cannot be attributed to corrosion-induced increase of notch root radius. Fair-sized lamellar cracks perpendicular to main crack direction have been present only in specimens pre-exposed in water, and in the present Authors opinion they could be due dissolution of sulfide inclusions accompanied by local hydrogenation of steel. However, numerous tests showed evident degradation of Charpy impact toughness energy of steels, c.f. Karpenko [9] and a literature survey by Smialowski [8]. The problem of the strain rate effect on hydrogen embrittlement of steels is discussed in literature. Smialowski suggested that the negative influence of hydrogen on impact properties of steels is weaker than on static properties. This is because under impact conditions the time of testing is not sufficient for hydrogen to diffuse into the process zone at the crack tip and a critical concentration of hydrogen cannot be approached. Tensile testing of smooth specimens also showed that the faster the strain rate the weaker the hydrogen-induced degradation of plasticity of steels is, and under dynamic loads and/or cryogenic temperatures hydrogen embrittlement did not occur [5,9]. Toribio and Kharin [14] have shown that the influence of load dynamics on hydrogen embrittlement is not unique. In the case of stress-controlled microfracture event in the process zone, the applied loading must be slow enough to allow hydrogen concentration to follow the evolution of the stress with negligible delay. However, in case of strain controlled micromechanism of fracture: "approaching in a dynamic manner the crack tip situation when hydrogen-assisted cracking may commence, local fracture event must occur at lower stress intensity factor than obtained in sustained load test. This way, load dynamics may act as promoter of hydrogen assisted cracking, which has been noted in some experiments"[14]. Thus, in the above analysis and experiments, hydrogen appears to be more or less damaging agent, never beneficial for impact propertied of smooth and notched steel specimens.

Previously the Author $[1,2]$ tested steel prestrained due to the grounding of ship hull bottom and after the repairing of the buckled region of plate. Karpenko [15] has shown that prestraining of steels can reduce their susceptibility to hydrogen embrittlement. This fact can be explained on the base of Zieliński and Domzalicki [6] statement that susceptibility of steels to hydrogen embrittlement is likely to be dependent on the amount of mobile hydrogen rather than trapped hydrogen.
Structural defects created by prestraining of the steel act as traps for hydrogen, therefore they can reduce the amount of diffusible hydrogen.

The present tests have been carried out in order to show what the influence of cathodic protection of ship hull structures on their mechanical properties is. Tensile testing and Charpy $\mathrm{V}$ impact tests have been chosen as common the acceptance mechanical tests for ship hull steels according to the rules of Classification Societies. The present investigations are continuation of preliminary ones $[1,2]$ but are based on steels of two different categories, and more numerous population of specimens of each of the steels while the steels were in asdelivered-to-shipyard condition (not pre-strained).

\section{TEST METHOD}

Two grades of ship hull plate steels have been testes: A and AH32 (denoted according to the rules of Classification Societies). Two types of specimens have been used for tensile testing: twelve smooth specimens of the diameter $\left(\mathrm{d}_{0}\right)$ equal 8 $\mathrm{mm}$ and the gage length $\left(\mathrm{L}_{0}\right)$ equal $40 \mathrm{~mm}$, and twelve notched specimens with the round notch profile very similar to Charpy $\mathrm{V}$ notch profile, but only $1 \mathrm{~mm}$ deep. The notched specimens diameter has been equal to $10 \mathrm{~mm}$, but diameter measured at the bottom of the V-groove has been equal to the smooth specimen diameter $(8 \mathrm{~mm})$ in order to avoid the scale-effect. Twenty two standard Charpy V specimens, but of reduced thickness equal $7.5 \mathrm{~mm}$, have been tested in different temperatures (room temperature of ca. $20^{\circ} \mathrm{C}, 0^{\circ} \mathrm{C},-20^{\circ} \mathrm{C},-40^{\circ} \mathrm{C}$ ). All the specimens have been divided into two groups. For each steel the first group (3 smooth and 3 notched specimens for tensile testing and 11 for Charpy impact testing) had been stored in room temperature air before testing without hydrogenation, while the second (analogous) group had been hydrogenated by cathodic charging before testing. The specimens of the second group had been submerged in $3.5 \%$ salt water and coupled to zinc anodes. Such conditions of hydrogenation are similar to conditions created by in-service cathodic protection of ship hull structures, although they are not strong as in numerous laboratory tests focused on hydrogen embrittlement problem.

The time necessary for hydrogen to diffuse from surface to the center of the specimen has been calculated by the following solution of the Second Fick's Law

where:

$$
\mathrm{X}_{0.5}=0.954 \sqrt{\mathrm{D}_{\mathrm{H}} \mathrm{t}}
$$

$\mathrm{X}_{05}$ - the distance of diffusion at which the hydrogen concentration $\mathrm{C}$ equals $0.5 \mathrm{C}_{0}\left(\mathrm{C}_{0}-\right.$ hydrogen concentration in the surface layer of steel)

$\mathrm{D}_{\mathrm{H}}$ - diffusion coefficient for hydrogen in the steel

$\mathrm{t}^{\mathrm{H}}$ - the time of diffusion

Putting the following values: $X_{05}=0.4 \mathrm{~mm}$ (half of the Charpy specimen thickness, because half of the tensile testing specimen was smaller), $\mathrm{D}_{\mathrm{H}}=10^{-7} \mathrm{~cm}^{2} / \mathrm{s}$, into the above equation, one can obtain $\mathrm{t}=1758918 \mathrm{~s}=21$ days. The specimens were hydrogenated for 60 days therefore real concentration of hydrogen is the specimens' center could be higher than 50\% of its concentration in the surface layer of the specimens. Zinc anodes were periodically cleaned in order to remove the surface oxide layer.

Among hydrogenated specimens all the tensile ones and some of the Charpy impact ones have been tested in room temperature directly after they were pulled out of the water and wiped dry. The Charpy impact specimens tested in lowered temperatures have been tested after a cooling period (denatured 
alcohol and liquid nitrogen) and wiped dry, but no longer than 20-25 minutes after the end of hydrogenation procedure.

The tests have been carried out according to the Polish Standards PN-EN 10002-1 (tensile testing) and PN-EN 10045-1 (Charpy impact test) and only geometry of the notched specimen for tensile testing was not standard.

\section{TEST RESULTS AND DISCUSSION}

Tension diagrams for smooth (unnotched) specimens are shown in Figs. 1 and 2. For hydrogenated specimens of the both steels tested the strength parameters, i.e. ultimate tensile strength UTS $\left(R_{m}\right)$, yield stress YS $\left(R_{e}\right)$ and a plasticity parameter elongation after fracture (A) are slightly higher than for as-received (not hydrogenated) steel specimens. Tension diagrams for notched specimens are not reported in the present paper. The same tendency is evident on the base of averaged data summarized in Table 1, (each value represents an average based on 3 specimens).

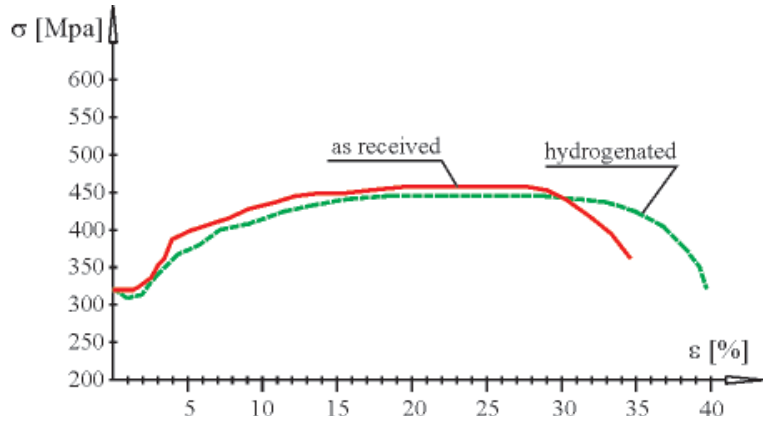

Fig. 1. Comparison of the tensile diagrams for an as received specimen to a hydrogenated one of ordinary strength steel grade A

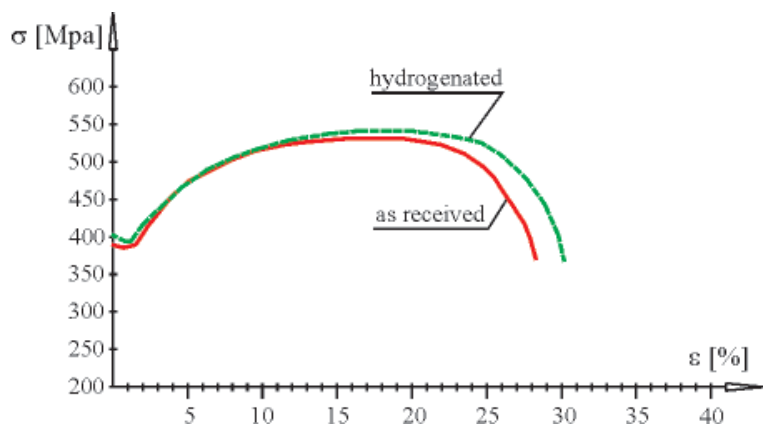

Fig. 2. Comparison of the tensile diagrams for an as received specimen to a hydrogenated one of higher strength steel grade AH32

Table 1. Averaged results of tensile testing

\begin{tabular}{|c|c|c|c|c|c|c|c|}
\hline steel & 窇 \& & 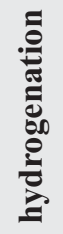 & $\begin{array}{l}A_{5} \\
\%\end{array}$ & $\begin{array}{l}\mathbf{Z} \\
\%\end{array}$ & $\begin{array}{c}\mathbf{R}_{\mathrm{e}} \\
\mathbf{M P a}\end{array}$ & $\begin{array}{c}\mathbf{R}_{\mathrm{m}} \\
\mathbf{M P a}\end{array}$ & 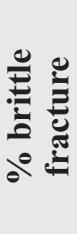 \\
\hline \multirow{4}{*}{ A } & \multirow{2}{*}{ plain } & no & 36.8 & 68.3 & 309.2 & 449.2 & 0 \\
\hline & & yes & 38.9 & 68.3 & 327.1 & 446.5 & 0 \\
\hline & \multirow{2}{*}{ notched } & no & 8.9 & - & 463.8 & 625.0 & 25 \\
\hline & & yes & 10.3 & - & - & 621.0 & 15 \\
\hline \multirow{4}{*}{ AH32 } & \multirow{2}{*}{ plain } & no & 33.0 & 79.3 & 392.8 & 533.4 & 0 \\
\hline & & yes & 32.6 & 70.4 & 408.7 & 535.4 & 0 \\
\hline & \multirow{2}{*}{ notched } & no & 6.7 & - & 612.4 & 747.1 & 0 \\
\hline & & yes & 8.3 & - & - & 735.8 & 0 \\
\hline
\end{tabular}

For smooth specimens the following effects of cathodic hydrogenation have been observed:

a it has increased yield stress $\left(R_{e}\right) 6 \%$ for A steel and $4 \%$ for AH32 steel

It has practically not changed ultimate tensile strength $\left(\mathrm{R}_{\mathrm{m}}\right)$ for the both steels

口 it has $6 \%$ increased elongation (A) for A steel and has not changed for AH32 steel

$\checkmark$ it has not changed the reduction of area $(Z)$ for A steel and decreased for AH32 steel.

So the influence of hydrogenation of the steel on its elongation (A) has appeared to be slightly beneficial, but the influence on the reduction of area $(Z)$ has appeared to be neutral or slightly detrimental. Analogous results have been obtained by Domzalicki et al [7] for an ordinary strength steel at cathodic potential $-0.8 \mathrm{~V}$ (SCE) without bacterias. In the present Authors opinion parameter $\mathrm{A}$ is more important from practical point of view because every static or quasistatic fracture is due to exceeding of critical ability of steel to elongation in certain conditions rather than the ability of the reduction of area.

For notched specimens hydrogenation has not influenced $\mathrm{R}_{\mathrm{m}}$ values and has caused a marked increase of elongation A (by $25 \%$ for A steel and by $33 \%$ for AH32 steel) although A-values for notched specimens are not representative, since they have been measured on the same gage length $(40 \mathrm{~mm})$ as for smooth specimens, while true plastic strains were concentrated very locally - in the notch root. Fracture appearance is also indicated in Table 1. All smooth specimens of both steels and the notched specimens of the higher strength steel AH32 fractured in a ductile mode but the notched specimens of steel A exhibited a mixed mode of fracture: ductile and brittle, and the hydrogenated specimens fracture surfaces are less brittle (average 15\% brittleness) than as-received ones (25\%).

Charpy V impact testing results are listed in Table II for individual specimens as well as averaged values for specimens grouped according to the same steel grade, testing temperature and preconditioning (as received or hydrogenated). Averaged values of Charpy $\mathrm{V}$ impact toughness energy (KV) are plotted in Fig. 3 and averaged values of percent ductility (fibrosity) of fracture surface are plotted in Fig. 4 versus the testing temperature. Both the Charpy fracture energy (KV) and the fracture appearance show that the hydrogenated steels behave less brittle than as-received ones. For ordinary strength steel A this beneficial effect of hydrogenation seems to be

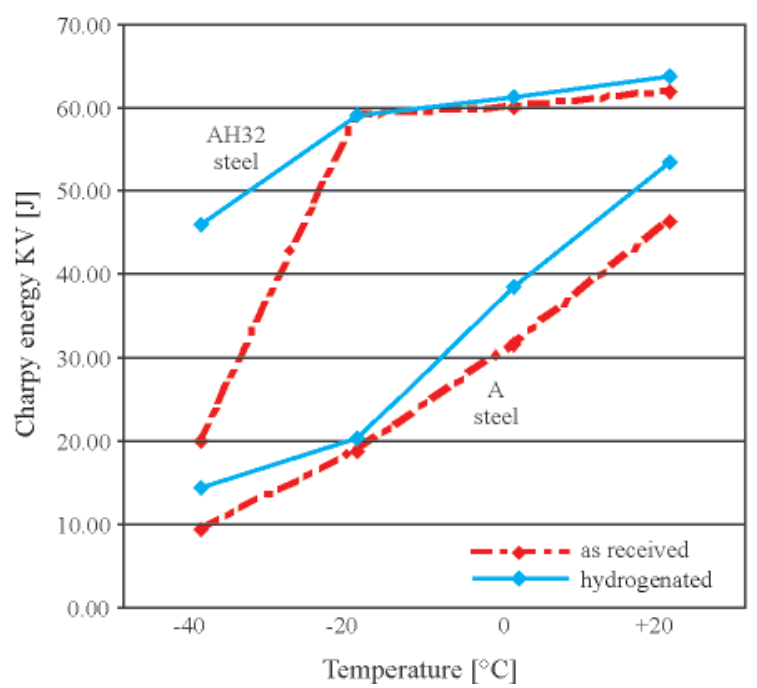

Fig. 3. Diagrams of Charpy V impact energy versus the testing temperature for both steels.(an ordinary strength A steel and a higher strength AH32 steel) in both an as-received and a hydrogenated conditions 
Table 2.

\begin{tabular}{|c|c|c|c|c|c|c|c|}
\hline ט & 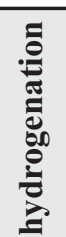 & steel & 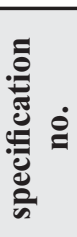 & fibr & sity & & \\
\hline \multirow{12}{*}{20} & \multirow{6}{*}{ no } & \multirow{3}{*}{ A } & 1 & 86.87 & \multirow{3}{*}{82.1} & 43 & \multirow{3}{*}{46.3} \\
\hline & & & 2 & 85.90 & & 50 & \\
\hline & & & 3 & 73.59 & & 46 & \\
\hline & & \multirow{3}{*}{ AH32 } & 4 & 100 & \multirow{3}{*}{100} & 61 & \multirow{3}{*}{62} \\
\hline & & & 5 & 100 & & 64 & \\
\hline & & & 6 & 100 & & 61 & \\
\hline & \multirow{6}{*}{ yes } & \multirow{3}{*}{ A } & 7 & 91.5 & \multirow{3}{*}{91.5} & 55 & \multirow{3}{*}{53.3} \\
\hline & & & 8 & 97.45 & & 53 & \\
\hline & & & 9 & 85.43 & & 52 & \\
\hline & & \multirow{3}{*}{ AH32 } & 10 & 100 & \multirow{3}{*}{100} & 63 & \multirow{3}{*}{63.7} \\
\hline & & & 11 & 100 & & 63 & \\
\hline & & & 12 & 100 & & 65 & \\
\hline \multirow{12}{*}{0} & \multirow{6}{*}{ no } & \multirow{3}{*}{ A } & 13 & 27.92 & \multirow{3}{*}{41.1} & 26 & \multirow{3}{*}{31.7} \\
\hline & & & 14 & 39.72 & & 32 & \\
\hline & & & 15 & 55.62 & & 37 & \\
\hline & & \multirow{3}{*}{ AH32 } & 16 & 100 & \multirow{3}{*}{100} & 60 & \\
\hline & & & 17 & 100 & & 60 & 60 \\
\hline & & & 18 & 100 & & 60 & \\
\hline & & & 19 & 62,36 & & 36 & \\
\hline & & A & 20 & 66.73 & 63.6 & 44 & 38.3 \\
\hline & & & 21 & 61.74 & & 35 & \\
\hline & yes & & 22 & 100 & & 61 & \\
\hline & & AH32 & 23 & 100 & 100 & 62 & 61.3 \\
\hline & & & 24 & 100 & & 61 & \\
\hline & & & 25 & 28.23 & & - & \\
\hline & & A & $25^{\prime}$ & 12.0 & 10 & 19.5 & 100 \\
\hline & & A & 26 & 24.65 & 18.4 & 17 & 18.8 \\
\hline & no & & 27 & 8.86 & & 20 & \\
\hline & & & 28 & 84.55 & & 56 & \\
\hline & & AH32 & 29 & 90.31 & 90.3 & 58 & 59 \\
\hline-20 & & & 30 & 96.00 & & 63 & \\
\hline & & & 31 & 16.77 & & 17 & \\
\hline & & A & 32 & 17.1 & 23 & 17 & 20.3 \\
\hline & & & 33 & 34.98 & & 27 & \\
\hline & yes & & 34 & 96.43 & & 56 & \\
\hline & & AH32 & 35 & 92.5 & 93.5 & 61 & 59 \\
\hline & & & 36 & 91.4 & & 60 & \\
\hline & & 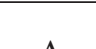 & 37 & 10.4 & 102 & 8.5 & 02 \\
\hline & & A & 38 & 10.2 & 10.3 & 10 & 9.3 \\
\hline & no & $4 \mathrm{H}_{22}$ & 39 & 42.5 & 302 & 18 & 20 \\
\hline 10 & & АНЗ2 & 40 & 33.83 & 39.2 & 22 & 20 \\
\hline-40 & & $\Delta$ & 41 & 16.5 & 88 & 17 & 145 \\
\hline & - & A & 42 & 1 & 8.8 & 12 & 14.5 \\
\hline & yes & $\hat{1}$ & 43 & 79.62 & 770 & 52 & 16 \\
\hline & & АН32 & 44 & 75.92 & $1 / .8$ & 40 & 40 \\
\hline
\end{tabular}

approximately independent of temperature judging by $\mathrm{KV}$ values, while reaches a maximum at a transition temperature judging by fracture appearance. For the higher strength steel AH32 the beneficial effect of hydrogenation increases as temperature decreases, but the specimens have not been tested in temperatures below $-40^{\circ} \mathrm{C}$ which seems to be close to ductilebrittle transition temperature, therefore the maximum beneficial effect of hydrogen can be at a temperature close to a transition one as it was for the ordinary strength steel.

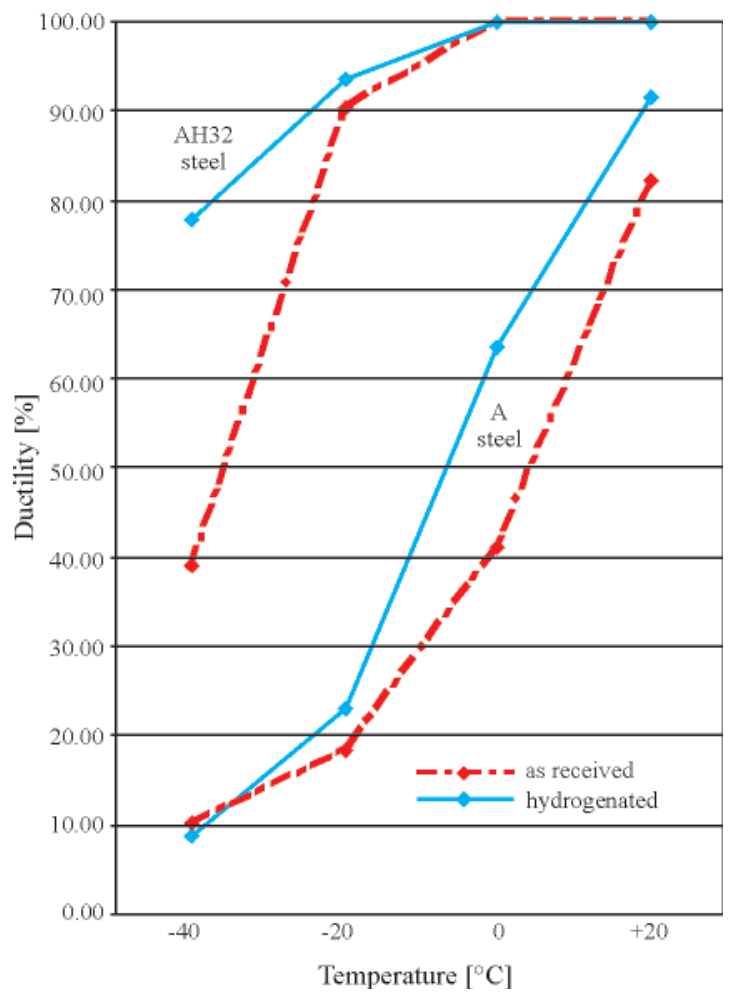

Fig. 4. Diagrams of percent fibrous (ductile) appearance versus the testing temperature for both steels. (an ordinary strength A steel and a higher strength AH32 steel) in both an as-received and a hydrogenated conditions

Fracture energy (KV) at any temperature can be considered as a sum of the energy absorbed to initiate fracture $\left(\mathrm{KV}_{\mathrm{i}}\right)$ and the energy to cause it to extent or propagate $\left(\mathrm{KV}_{\mathrm{p}}\right)[18]$ :

$$
\mathrm{KV}=\mathrm{KV}_{\mathrm{i}}+\mathrm{KV}_{\mathrm{p}}
$$

Newhouse [16] has stated that the crack initiation energy $\mathrm{KV}_{\mathrm{i}}$ is relatively constant throughout the ductile-brittle transition range of temperatures, while the crack propagation energy $\mathrm{KV}_{\mathrm{p}}$ varies with temperature. Although the independence of $\mathrm{KV}_{\text {i }}^{\mathrm{p}}$ on temperature is questioned sometimes [17], Newhouse' approach has been applied for the present analysis. The propagation energy is equal to energy absorbed by the cleavage (brittle) portion of fracture $\left(\mathrm{KV}_{\mathrm{pc}}\right)$ plus that absorbed by the fibrous (ductile) portion $\left(\mathrm{KV}_{\mathrm{pf}}\right)$ :

$$
\mathrm{KV}_{\mathrm{p}}=\mathrm{KV}_{\mathrm{pc}}+\mathrm{KV}_{\mathrm{pf}}
$$

It has been shown [16] "that an insignificant portion of the total energy measured in the Charpy impact test is absorbed in the brittle portion of the fracture and that almost all is due to fracture initiation, fibrous tearing and lip formation". The fracture propagation energy can be assumed as proportional to fibrous portion of the fracture surface $[16,17]$ thus in the transition range of temperature:

$$
\mathrm{KV}=\mathrm{KV}_{\mathrm{i}}+\mathrm{kx}
$$

where: $\mathrm{x}$ is the percent of fibrous (ductile) fracture, and $\mathrm{k}$ is a constant. 
Diagrams KV versus $x$ are presented in Figs 5-8. Following Newhouse approach, each point in these diagrams represents values $\mathrm{KV}$ and $\mathrm{x}$ for an individual specimen. Equations (3) evaluated by the least square method as well as the correlation coefficients $\mathrm{R}^{2}$ values are shown in the figures. Following values of fracture initiation energy $\mathrm{KV}_{\mathrm{i}}$ have been obtained:

* 10.5 for as received A steel

* 9.6 for hydrogenated A steel

* -5.6 for as received AH32 steel

* -7.4 for hydrogenated AH32 steel

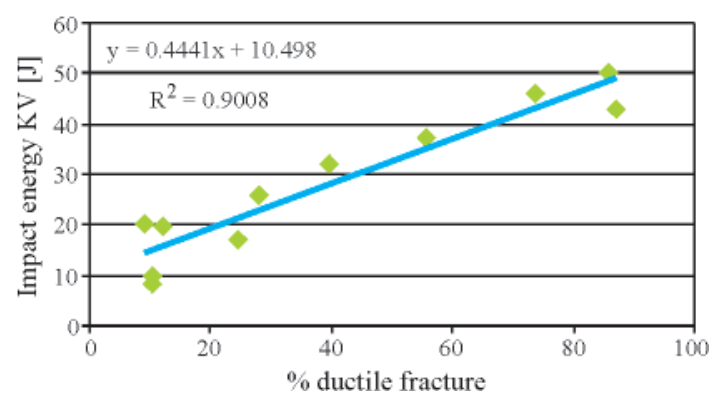

Fig. 5. Relation between Charpy $V$ energy and percent of ductile (fibrous) fracture appearance for as received A steel

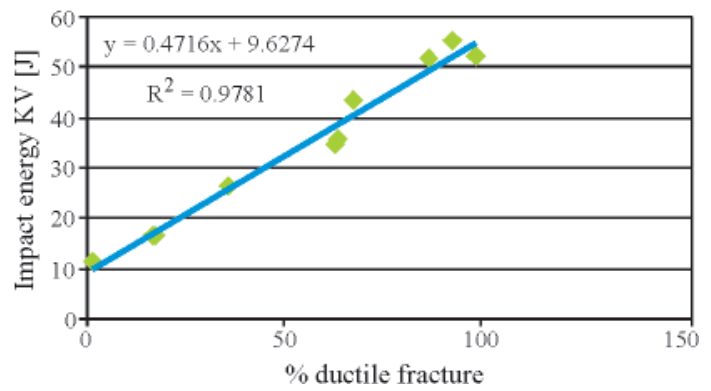

Fig. 6. Relation between Charpy $V$ energy and percent of ductile (fibrous) fracture appearance for hydrogenated A steel

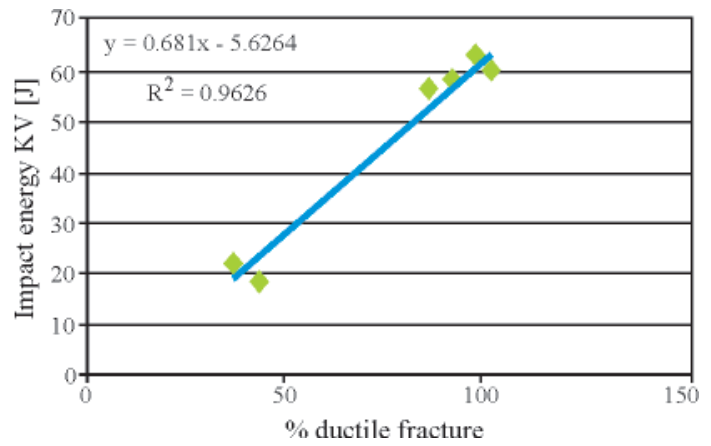

Fig. 7. Relation between Charpy V energy and percent of ductile (fibrous) fracture appearance for as received AH32 steel

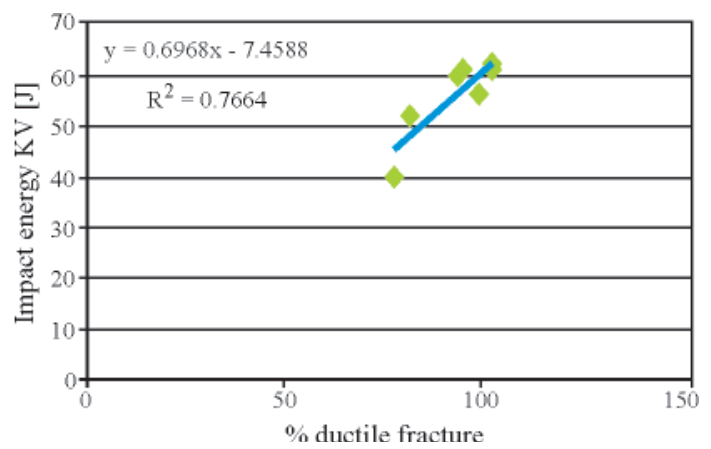

Fig. 8. Relation between Charpy $V$ energy and percent of ductile (fibrous) fracture appearance for hydrogenated AH32 steel
Hydrogenation caused the reduction of the crack initiation energy for A steel (by 8\%) and forAH32 steel, but both values for the second steel are below zero. Newhouse reported such results as occasional ones and attributed them to "error in measurement of fracture appearance, particularly at low fibrosity levels" In the present tested temperatures range the overwhelming majority of specimens of the AH32 steel exhibited relatively high fibrosity levels with only two specimens with medium fibrosity, therefore the values of $\mathrm{KV}_{\mathrm{i}}$ have been evaluated by far extrapolation of the curve based on data for relatively high fibrosity levels to the nil ductility level with an inevitable error. It has appeared that hydrogen reduced the crack propagation energy for steel A only slightly and beneficial effect of hydrogenation on Charpy impact energy concerns mainly the crack propagation energy. Indeed, the Newhouse approach has appeared not to be successful in the present case of AH32 steel, but one can risk an opinion that energy $\mathrm{KV}_{\mathrm{i}}$ for the steel is presumably lower than for steel A.

For present specimens of reduced thickness $7.5 \mathrm{~mm}$ the minimum Charpy energy required by the rules of the Classification Societies is equal to $5 / 6$ of the energy for full thickness $10 \mathrm{~mm}$ specimens and the energy required for the present A and AH32 steels equals 22.5J and 25.8J respectively. The transition temperature, at which the Charpy energy drops below its required value, for A steel equals $-14^{\circ} \mathrm{C}$ for asreceived and $-18^{\circ} \mathrm{C}$ for cathodically hydrogenated specimens, while for $\mathrm{AH} 32$ steel the temperature is $-36^{\circ} \mathrm{C}$ and below (probably well below) $-40^{\circ} \mathrm{C}$ for as-received and hydrogenated steel respectively.

Charpy fracture appearance is preferred to Charpy energy $\mathrm{KV}$ as a fracture resistance indicator because of its more direct physical significance [18]. It is also more independent of specimen thickness thinner than $10 \mathrm{~mm}$ and notch orientation, while Charpy energy is sensitive to both [18]. Newhouse [16] and Sumpter et al [18] have considered fracture appearance transition temperature (FATT) corresponding to 50\% ductile fracture as a very meaningful parameter. FATT for the present A steel equals $+4^{\circ} \mathrm{C}$ for as-received and $-7^{\circ} \mathrm{C}$ for hydrogenated conditions, while for AH32 steel FATT equals -37 for asreceived and well below $-40^{\circ} \mathrm{C}$ for hydrogenated conditions.

Although air temperature may fall as low as $-15^{\circ} \mathrm{C}$ without the sea becoming frozen, it is very likely under those conditions that extensive icing of the decks would limit the steel temperature to not much below the freezing point of seawater $\left(-2^{\circ} \mathrm{C}\right)[18]$. Temperature $0^{\circ} \mathrm{C}$ covers most of practical interest. There is an opinion [18] that criterion of less than $70 \%$ of cleavage fracture (more than $30 \%$ fibrosity) at $0^{\circ} \mathrm{C}$ ensure a satisfactory level of resistance to cleavage fracture initiation of ship structures at the same temperature [18]. The present A steel in as-received condition is on the edge of this criterion (one of the specimens does not satisfy the criterion), while hydrogenation has shifted the steel into a safety region far from the edge. What is more, hydrogenation of the steel has enabled to fulfill a criterion of minimum $50 \%$ fibrosity at $0^{\circ} \mathrm{C}$ that should ensure a Robertson crack arrest temperature below $0^{\circ} \mathrm{C}[18]$ (this criterion concerns minimum $50 \%$ fibrosity at $0^{\circ} \mathrm{C}$, while the above mentioned FATT concerns on an average 50\% fibrousity at any temperature). For arrest of very long cracks in ship structures a $100 \%$ fibrous fracture appearance at $0^{\circ} \mathrm{C}$ is considered desirable [18] and the present A steel has not satisfied the criterion. The present AH32 steel in both conditions satisfies all the above criteria: minimum $30 \%$ and minimum $50 \%$ and $100 \%$ fibrosity with a large margin of safety.

Thus the present test results are qualitatively similar to preliminary test results $[1,2]$. The beneficial effect of hydrogen is not easy to explain. There are, however, some regularities 
in the results that could be taken into account in a formulation of a hypothesis:

$\Rightarrow$ Continuous decrease of a detrimental effect of hydrogen on mechanical properties of steels with increase of the steels deformation rate has been reported by numerous investigators, so it has temporarily been hypothesized [1, 2] that a beneficial effect of hydrogen can appear for very high deformation rates as in Charpy test. This working hypothesis is, however, inconsistent with numerous Charpy tests data for steels and only the present Authors investigations results support this hypothesis.

$\Rightarrow$ In every case of notched specimens the beneficial effect of hydrogenation is more evident than for smooth ones, e.g. a marked increase of elongation $A$ and decrease of fracture appearance brittleness for hydrogenated specimens in tensile testing The notched specimens were hydrogenated in unstressed condition thus locally increased hydrogen concentration due to stress concentration at the notch root had not been reached before testing. The relation between the presence of notch and hydrogenation effect can be, however, considered as the effect of strain rate too, since in static tensile testing the deformation rate in notch root is always higher than the rate in plane specimen, but lower than for Charpy V specimen in impact test.

$\Rightarrow$ The present hydrogenation conditions (the applied potential and near-neutral electrolyte without any promoter of hydrogenation) were not so strong as in numerous studies on hydrogen effects on steels properties. Cathodic deposits visible on the specimens surfaces could additionally reduce the hydrogenation intensity. Therefore hydrogen concentration in the present tests could not be as strong as in other tests. Extensive investigations of numerous steels after high-temperature hydrogenation [12] have also exhibited evidently beneficial effect of hydrogenation on mechanical properties of the steels on condition that hydrogen pressure, temperature and hydrogenation duration were small enough to avoid hydrogen-induced corrosion (mainly: decarburization) and hydrogen concentration was not very high, i.e. moderate. In the present investigations the moderate concentration means the value of concentration reached at a potential about $-1.05 \mathrm{~V}$, while in SSRT realized by Domzalicki et al [7] it was another value reached at $-0.8 \mathrm{~V}$. So the value of concentration denoted above as "moderate" depends on the strain rate, but perhaps on hydrogenation conditions too - in the present tests the cathodic potential was applied before the testing and some, but not large, degree of desorption of hydrogen from subsurface layer of steel can be expected in spite of short time distance between the end of hydrogenation procedure and the end of a test, while in Domzalicki et al investigations the appropriate cathodic potential was applied during testing and desorption was impossible.

Some published test results seem to be inconsistent with the above regularities. For example numerous data [19] show a marked reduction of critical values of the stress intensity factor $\left(\mathrm{K}_{\mathrm{Q}}, \mathrm{K}_{\mathrm{IC}}\right.$ or $\left.\mathrm{K}_{\mathrm{I} \rho}\right)$ in spite of the fact that the values have been evaluated by testing of notched and usually precracked specimens. On the other hand a diagram [19] show that for a steel containing low hydrogen concentrations an increase of the concentration causes a significant decrease of $\mathrm{K}_{\mathrm{O}}$ at a lower deformation rate and does not influence $\mathrm{K}_{\mathrm{Q}}$ at a higher deformation rate. It cannot be excluded that, in fact, a combination of the three above conditions should be satisfied jointly for the beneficial effect of hydrogen to occur, i.e.:
- deformation rate is high enough

- notch is sharp enough if specimens have been cathodically protected in unstressed conditions

- hydrogen concentration is moderate

\section{CONCLUSIONS}

Static tensile testing of notched and smooth specimens and Charpy V impact testing have been carried out. An ordinary strength ship steel grade A and a higher strength steel grade AH32 in as received (not hydrogenated) and hydrogenated by cathodic protection (zinc) in salt water have been tested. The following conclusions have been drawn:

Hydrogenation of steels have slightly increased yield strength $\left(R_{e}\right)$ and elongation after the fracture $(A)$ of both steels, it has not influenced ultimate tensile strength $\left(R_{m}\right)$ of the both steels and reduction or area $(Z)$ of the ordinary strength steel, while it has reduced $Z$ for the higher strength steel. Notched specimens of the ordinary strength steel have exhibited a mixed mode fracture and the hydrogenated specimens have exhibited less brittle fracture appearance than as-received specimens. Thus the influence of hydrogenation on static tensile testing properties for the ordinary strength steel has been slightly less detrimental or even more beneficial than for the higher strength steel.

Charpy $\mathrm{V}$ impact testing has shown that hydrogenation of both steels increased Charpy energy and percent fibrousity of fracture and shifted down ductile-brittle transition temperatures both energy-based and fractureappearance-based (FATT) ones. It is mainly due to the effect of hydrogenation on the fracture propagation energy. In ship service temperature $0^{\circ} \mathrm{C}$ is very important. The tested steels in as received and in hydrogenated conditions have satisfied minimum $30 \%$ of fibrousity at $0^{\circ} \mathrm{C}$ criterion (that ensures satisfactory crack initiation resistance at this temperature), although the ordinary strength steel tested without hydrogenation has been on the edge of this criterion. Hydrogenation of the ordinary strength steel have also enabled to satisfy the minimum 50\% of fibrousity criterion that ensures a Robertson crack arrest temperature below $0^{\circ} \mathrm{C}$. A $100 \%$ of fibrousity criterion for arrest of very long cracks is satisfied only for the higher strength steel in the both conditions.

O A common current practice to evaluate mechanical properties of ship steels by testing the specimens that have not been hydrogenated leads to conservative results. A case of notched steels hydrogenated in stressed conditions have to be, however, recognized in future.

The present ordinary strength steel A has satisfied the Classification Societies requirements for B steel, while the higher strength steel $\mathrm{AH} 32$ satisfied the requirements for DH40 steel.

The present author hypothesize that the following conditions are necessary for beneficial effect of hydrogenation on mechanical properties of steels to occur:

- hydrogen concentration is moderate;

- notch is sharp enough (valid presumably for specimens hydrogenated in unstressed conditions only);

- deformation rate is fast enough. 


\section{BIBLIOGRAPHY}

1. M. Jakubowski: Causes of the crack in the bottom plating of $\mathrm{m} / \mathrm{s}$ „Beskid”, An expert opinion (unpublished) (in Polish), Gdansk University of Technology, Gdansk 2003

2. M. Jakubowski: Could local buckling of bottom plating of a small tanker be an immediate reason of crack in the structure? (in Polish), Proc. 21-th Symposium on Fatigue and Fracture of Materials and Structures, Bydgoszcz-Pieczyska, May 23-26, 2006, pp. 139-147

3. D. Le Friant, B. Bayle, C. Adam, Th. Magnin: Stress corrosion cracking of X52 pipeline steel in deoxygenated dilute aqueous solution, Proc. Int. Conf. on Environmental Degradation of Engineering Materials, 19-23 Sept. 1999, Gdansk-Jurata, Poland, Vol. I, pp. 168-173

4. E. Lunarska, D, Samatowicz, E. Sitko: Hydrogen embrittlement of $30 H G S N A$ aircraft steel in $\mathrm{Cl}^{-}$containing environments, Proc. Int. Conf. on Environmental Degradation of Engineering Materials, 19-23 Sept. 1999, Gdansk-Jurata, Poland, Vol. I, pp. 334-339

5. K. Pokhodnya, V.I. Shvachko, S.M. Stepanyuk: Experimental modeling of cold cracking of structural steels and welds, Proc. Int. Conf. on Environmental Degradation of Engineering Materials, 19-23 Sept. 1999, Gdansk-Jurata, Poland, Vol. I, pp. 351-356

6. A. Zieliński, P. Domżalicki: Hydrogen degradation of high-strength low-alloyed steels, J. of Materials Processing Technology, 2003, Vol. 133, pp.230-235

7. P. Domżalicki, E. Łunarska, D. Kwiatkowska, H. Wichary, J. Birn: Effect of cathodic polarization in microorganismscontaining seawater on mechanical properties of steels (in Polish), Ochrona przed korozja, 2004, No. 12, pp. 338-340

8. M. Śmiałowski: Hydrogen in steels, publishers (in Polish). WNT, Warsaw 1961

9. G.V. Karpenko, Strength of steels in corrosive environment, publishers (in Russian). Mashgiz, Moscow-Kiev 1963

10.L.S. Moroz, B.B. Chechulin: Hydrogen embrittlement of metals (in Russian), Publishers: Metallurgia, Moscow 1967

11.E. Lunarska: Effect of hydrogen on the iron plasticity (in Polish), Scientific Bulletins of the Stanislaw Staszic University of Mining and Technology, No. 997, series: Metallurgy and Foundry Practice, Bulletin 101,(monography), Kraków 1984

12. Yu. I. Archakov: Hydrogen corrosion of steels (in Russian), publishers.: Metallurgia, Moscow 1985

13.J. Juraszek, J. Nowak, Z. Jurasz: Effect of corrosion on mechanical properties of ship hull plate steels, Proc. Int. Conf. on Environmental Degradation of Engineering Materials, 19-23 Sept. 1999, Gdansk-Jurata, Poland, Vol. II, pp.73-76

14.J. Toribio, V. Kharin: Load dynamics effects on cracktip hydrogen accumulation in metals, Proc. Int. Conf. on Environmental Degradation of Engineering Materials, 19-23 Sept. 1999, Gdansk-Jurata, Poland, Vol. I, pp. 399-404
15.G.V. Karpenko: Serviceability of structural materials in aggressive environments (in Russian), publishers: Naukova Dumka, Kiev 1985

16.D.L. Newhouse: Relationship between Charpy impact energy, fracture appearance and test temperature in alloy steels. Welding Journal, 1963, no. 3, pp. 105s-114s

17.M. Szkodo, Z. Zaczek: Application of D.L. Newhouse method in estimation of the energy to initiate fracture in quenched and tempered 18G2A steel (in Polish). Scientific Bulletins of Gdansk University of Technology, No. 425, Series: Mechanics, No. LV, pp. $11-20$

18.J.D.G. Sumpter, J. Bird, J.D. Clarke, A.J. Caudrey: Fracture toughness of ship steels, The Transactions of The Royal Institution of Naval Architects, Vol. 131, 1988, pp.169-177

19.S.E. Kovchyk, E.M. Morozov: Fracture Mechanics and material strength (in Russian), Vol. 3, Publishers: Naukova Dumka, Kiev 1988

\section{NOMENCLATURE}

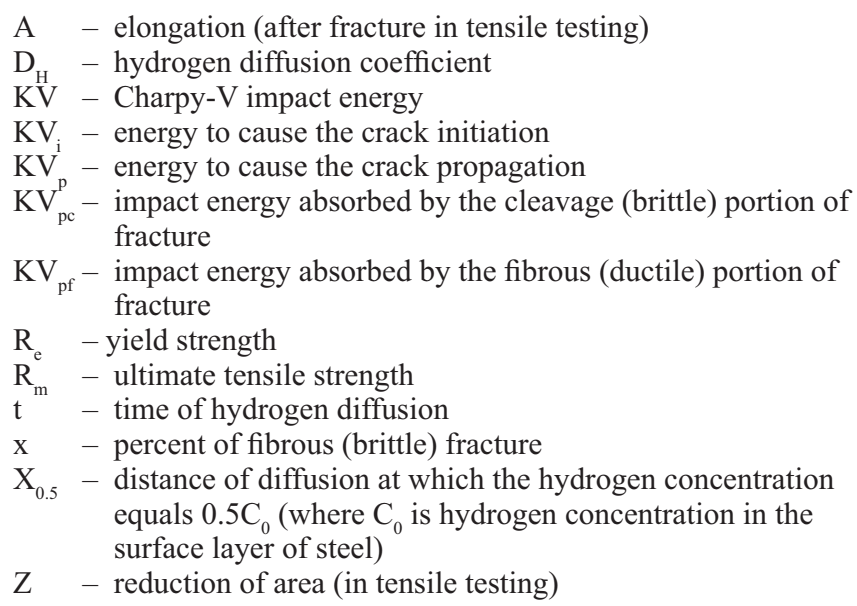

\section{ABBREVIATIONS}

FATT - fracture appearance transition temperature SSRT - slow strain rate test

\author{
CONTACT WITH THE AUTHOR \\ Assoc. Prof. Marek Jakubowski \\ Faculty of Ocean Engineering \\ and Ship Technology \\ Gdansk University of Technology \\ Narutowicza 11/12 \\ 80-952 Gdansk, POLAND \\ e-mail :marjak@pg.gda.pl
}

